\title{
IDÉIAS
}

por ocasião do lançamento do Programa de Estabilização Econômica.

Sem o engajamento ocorrido, não se teria logrado êxito, apesar de todas as leis e de todos os órgãos existentes e que têm como finalidade a defesa do consumidor.

Em razāo da prática administrativa e do papel que se exige do Estado moderno, faz-se necessária a revisão da legislação atual, com a edição de uma lei orgânica que estabeleça os principios gerais pelos quais deve pautar-se a administração pública, permitindo-lhe, porém, a flexibilidade necessária ao cumprimento oportuno e eficaz do seu papel.

Finalmente, vem a componente da qual depende fortemente o êxito de qualquer movimento de reforma e modernização da Administração Pública: os seus recursos humanos.

Destes, 540.000 estão em atividade na Administração direta e nas autarquias. Dentre eles, contam-se 126.000 estatutários e 410.000 celetistas. Há ainda 170.000 inativos e 136.000 pensionistas, de acordo com informacões da Sepec/Dasp. Além disso, as empresas públicas e as sociedades de economia mista contam com 629.721 servidores, enquanto que as fundaçoes abrigam outros 90 mil e os bancos federais, 187.513

$\mathrm{O}$ servidor público federal está hoje com a imagem de certa forma comprometida perante a opinião pública, não por sua culpa, mas por circunstâncias que o desmotivaram para o exercicio de um serviço público realmente ágil e eficiente.

Com um Estatuto que data de 1952, com um plano de classificação de cargos que, embora tenha pouco mais de 10 anos, encontra-se eivado de inadequaçoes, não há como motivar o servidor público para reforma alguma $e$, portanto, não há como reformar.

Com a sensibilidade politica que the é peculiar, o ministro Aluizio Alves vem trabalhando decididamente para reverter este quadro. Empenhado no desenvolvimento $\mathrm{e}$ implantação de um novo Estatuto, de um novo Plano de Classificação e Funçōes, de um Plano de Previdência e Assistência ao Funcionário Público, de um Plano de Formaçảo e Desenvolvimento de Recursos $\mathrm{Hu}$ manos, o Ministro da Administracảo está criando condições para que possa ser realmente efetivada uma reforma profunda da Administracão Pública Federal.

\section{Por uma política de informação documental}

\author{
Adelaide Ramos e Córte (")
}

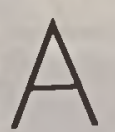

Reforma Administrativa é um espaço aberto para se informação documental para o setor público onde as decisðes deverão deixar de ter o caráter casuístico e passar para um esinformaçao, tendo em vista a necesmas e de sua não descaracterização a cada gestão.

O Governo da Nova República trouxe de volta ao cidadão brasileiro vencer os obstáculos que o impedem de ter uma vida saudável. Exemplo disso é o empenho de todos no sucesso da nova política econômica adotada pelo Governo.

A esperança de mudanças é sentida em todos os segmentos da sociedade. Neste cenário, surge o Plano de Reforma da Administração Fedequina estatal, de valorizar o servidor público e de tornar o setor público eficiente, como bem o diz o professor Belmiro Siqueira.

A Reforma Administrativa oporluniza a participação democrática neste processo de mudança de estruturas, que é considerado vital para o compromisso democrático do Governo da Nova República.

Nesta perspectiva, faz-se necessário atentar para o problema da Informação Documental e sua importância como suporte às decisð̃es gomais especificamente na Administração Pública. estabelecer uma politica de tágio de ação decisória baseada na sidade de continuidade dos prograo desejo de lutar e a esperança de ral com o objetivo de agilizar a mávernamentais no cenário brasileiro e

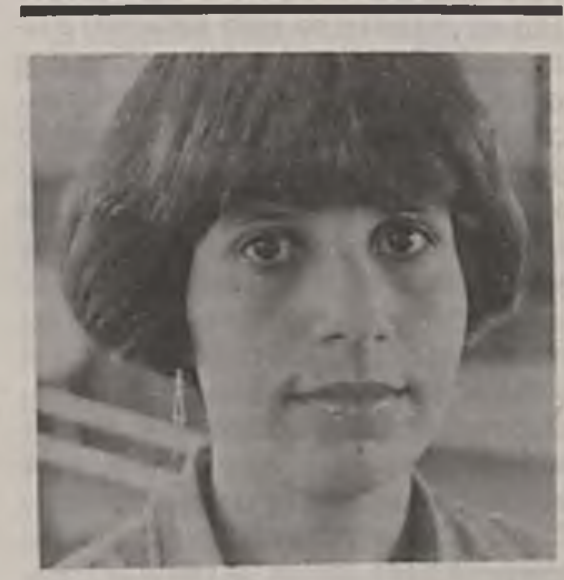

Informação documental é a informacão técnica, cientfica, cultural, educacional e administrativa, que, estando sob qualquer tipo de suporte (livro, revista, mapa, fita magnética, disco, disquete, microformas, etc), tem por objetivo transferir ou transmitir conhecimentos gerados ou produzidos por uma pessoa ou por uma instituição.

O conhecimento produzido nāo tem valor se não for divulgado. Ele deve ser transferido à sociedade que dele fará uso para melhorar, aplicar e até mesmo gerar um novo conhecimento.

A qualidade da informação disponivel para a sociedade, tanto o individuo quanto o grupo, determina o grau de desenvolvimento desta sociedade e o nivel de vida do cidadão é caracterizado pelo critério de uso da informação quando da decisāo de seus problemas.

Neste sentido, a informação
(-) Graduada pela Universidade de Brasilia em Biblioteconomia e Documentaçáo,

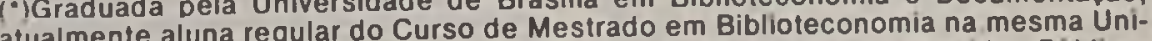
versidade. Bibliotecária da Fundaçáo Centro de Formaçáo do Servidor PúblicoFuncep. 


\section{IDÉIAS}

torna-se vital tanto para a subsistência do indivíduo como da Sociedade. E por isso é preciso torná-la disponivel para o cidadão; é necessário considerá-la como um serviço de utilidade pública, um serviço que existe para o bem comum, onde é oferecida ou tornada acessivel e disponivel em quantidade e qualidades suficientes para atender os anseios individuais e da coletividade.

Não se pode buscar a democracia sem considerar que o reencontro da via democrátiça se dá através da democratização da informação. A proposta da Reforma Administrativa é aumentar o grau de participação do cidadão na vida nacional $\mathrm{e}$ isto equivale a desenvolver meios que permitam o livre acesso à informação, para transmitir o conhecimento produzido, o que levará o individuo a conscientizar-se de seu papel na sociedade e identificar-se com os seus valores mais autênticos.

Estabelecer uma politica de informação para o setor público é necessário e urgente. Implica em dar condiçōes físicas, financeiras e humanas aos setores responsáveis pela busca, tratamento, preservação e difusão de conhecimentos, papéis desempenhados pelos Arquivos, Bibliotecas e Museus nas organizaçð̃es.

Essa política permitirá fixar diretrizes filosóficas quanto à geração, tratamento e uso racional de documentos e informaçōes, de modo a permitir não só o apoio efetivo is açōes governamentais a as necessidades do usuário do serviço público, mas também a preservação da memória nacional.

Ė necessário investir no desenvolvimento e na melhoria do tratamento dos acervos documentais e dinamizar a utilizaça dos produtos e serviços informacionais, utilizandose equipamentos modernos para permitir a transferência do conhecimento de maneira eficiente.

Todo cidadão que faz uso racional dos recursos e serviços informacionais oferecidos pelas biliotecas, arquivos e museus, na administração pública, como suporte às suas atividades profissionais, percebe que, nos últimos anos, esses serviços foram totalmente excluidos das prioridades de governo. O hiato entre a geração e a divulgação do co-

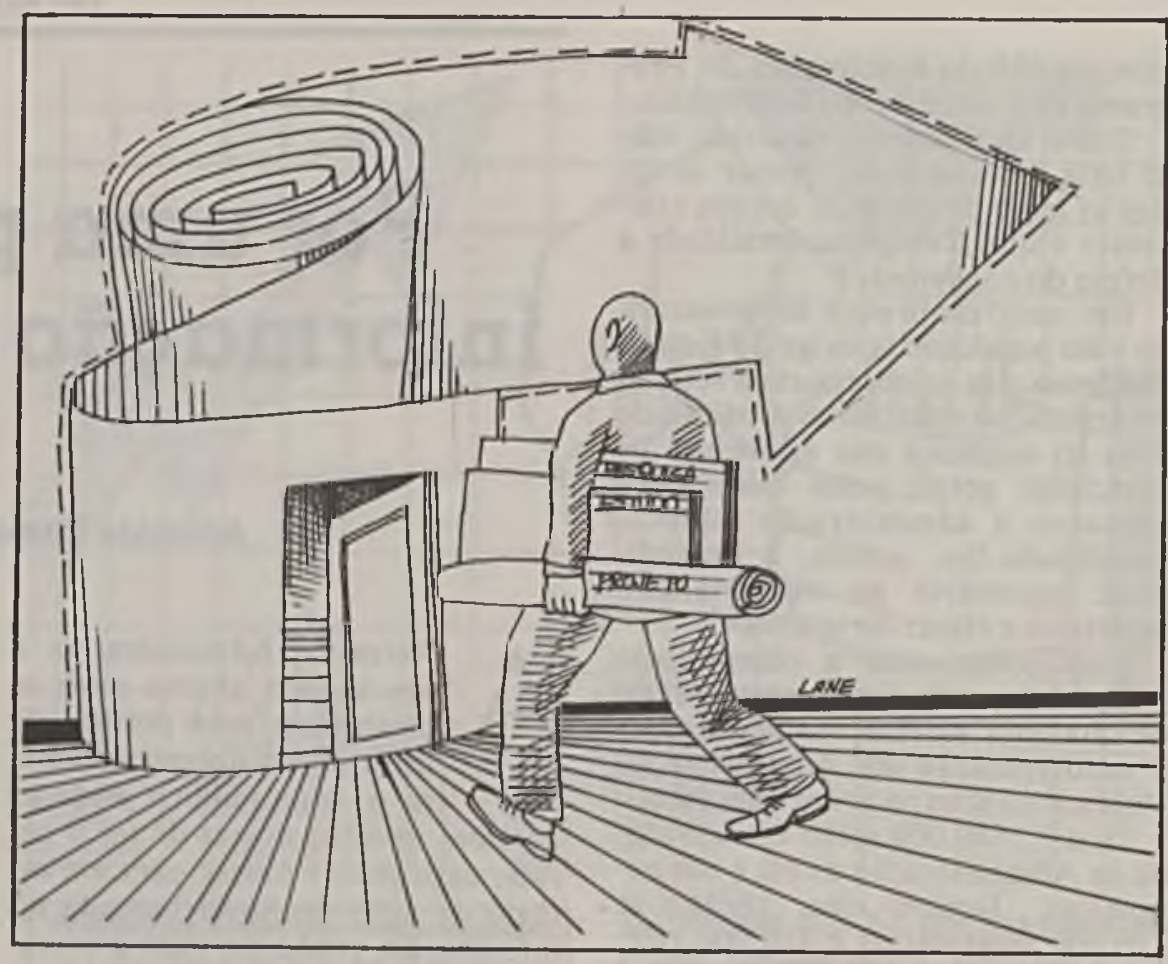

A máquina estatal só passará a produzir em sua plenitude, quando o servidor público voltar a fazer uso da informação registrada, para tomar decisões, desenvolver projetos, estudos e pesquisas. Assim, as decisões deixarão de ter caráter casuístico e passarão a um estágio de ação decisória baseada na informação.

nhecimento torna-se cada dia maior.

Acervos documentais desatualizados, arquivos destruídos, escassez de recursos financeiros e materiais, desmotivação dos servidores såo fatos plenamente constatáveis nestes setores.

A máquina estatal só passará a produzir em sua plenitude, quando o servidor público voltar a fazer uso da informação registrada para tomar decisōes, desenvolver projetos, estudos e pesquisas. Neste momento, as decisðes deixarão de ter o ca- ráter casuistico e passarão a um estágio de ação decisória baseada na informação, principalmente pela necessidade de continuação dos programas, projetos e açðes no sentido de não descaracterizá-los a cada gestão.

A Reforma Administrativa surge como esperança de que esta situação seja alterada e que, de fato, possa ser estabelecida uma politica de informação na Administração Pública. Para tanto, foi criada na Comissão de Coordenação do Plano de Reforma da Administração Federal, a Comissão Especial para Preservação do Acervo Documental - CE$P A D$, integrada por profissionais de comprovada experiência nas áreas de Arquivologia, Biblioteconomia e Museologia, para juntos, num trabalho cooperativo e integrado, desenvolverem estudos que, subsidiados por um diagnóstico, resultem em propostas concretas e possiveis de serem executadas na tentativa de dar à informação documental o seu real valor.

É preciso, pois, que, obedecendo a preceitos democráticos, adote-se uma política de informaçao documental para o Setor Público, tornando a informação um bem social, nela reconhecendo um direito do cidadão tão importante e necessário quanto à educação, o trabalho e a saúde. 